\title{
Moro Reflex: A Mini Review of Literature
}

\author{
Sreeram Ravi, BA, BS, MS, Phillip J Stokey MD*, Nabil A Ebraheim MD \\ Department of Orthopedic Surgery, University of Toledo College of Medicine and Life Sciences, USA.
}

*Corresponding Author: Phillip J Stokey, Department of Orthopedic Surgery, University of Toledo College of Medicine and Life Sciences, USA.

\section{Received Date: 14 October 2021 | Accepted Date: 14 December 2021 | Published Date: 07 January 2022}

Citation: S Ravi, Phillip J Stokey, Nabil A Ebraheim. (2022). Moro Reflex: A Mini Review of Literature. J. Clinical Surgery and Research. 3(1); DOI:10.31579/2768-2757/035

Copyright: (C2022 Phillip J Stokey, This is an open-access article distributed under the terms of the Creative Commons Attribution License, which permits unrestricted use, distribution, and reproduction in any medium, provided the original author and source are credited.

\begin{abstract}
The Moro reflex is an infantile primitive reflex that is normally present in all infants and newborns. The Moro reflex is normally seen at birth and it is an involuntary response to stimulation or abrupt body displacement. The reflex was first described by Austrian pediatrician Ernst Moro in 1918. It develops between the 28 and 32 weeks of gestation and disappears at 3-6 months of age. Abnormalities of the Moro reflex is highly specific for a variety of perinatal injuries and defects.

Keywords: moro reflex; infantile primitive reflex; newborns; spastic-type cerebral palsy
\end{abstract}

\section{Introduction}

The Moro reflex is an infantile primitive reflex that is normally present in all infants and newborns. The Moro reflex is normally seen at birth and it is an involuntary response to stimulation or abrupt body displacement. The reflex was first described by Austrian pediatrician Ernst Moro in 1918. It develops between the 28 and 32 weeks of gestation and disappears at 3-6 months of age [1-4].

The doctor will check for the reflex after birth and during well child visits. This reflex is present as a response to a sudden loss of support. The infant feels as if it is falling. To elicit this reflex, the infant's head is gently lifted with enough support to begin to move the body weight of the infant from the examination table. The support of the infant is then suddenly released allowing the infant's head to drop a few centimeters in relation to the body, but then quickly supported again [5-7]. The normal response is for the infant to have a startled look. As the reflex ends, the infant draws its arms back to the body and relaxes. The role reflects involves three distinct components [8-10].

- Spreading out of the arms (abduction)

- Unspreading of the arms (adduction)

- Crying (usually)

\section{Clinical Significance}

Absence of the Moro reflex in infants is abnormal as the Moro reflex is an indicator of early nervous system function. Abnormal response can result from many different causes but typically occur from trauma during birth. Other causes of abnormal or absent Moro reflex include infection, congenital malformation of the CNS and spastic-type cerebral palsy [11, 12]. If the reflex is absent or abnormal, tests may be needed to examine the child's muscles. These tests may include shoulder x-rays or tests for disorders associated with a brachial plexus injury [8].

Absence on both sides suggests damage to the brain or spinal cord. Absence on only one side suggests either a broken shoulder bone or an injury to the brachial plexus $[12,13]$. Infants that are born vaginally with forceps may not move correctly and suffer an injury to the upper extremity and have a subsequent brachial plexus injury. An intact Moro reflex signals that the infant does not have a true brachial plexus injury. Palpation of the shoulder may cause the infant cry. Infant may have an associated clavicle fracture [14].

\section{Differential Diagnosis}

Clavicle fracture with pseudoparalysis is the most common cause of abnormal Moro reflex in infants. Isolated clavicle fracture is most common of this type of pseudoparalysis and these infants typically have an intact Moro reflex and will likely recover in 7-10 days from the pseudoparalysis with conservative treatment. These patients should be followed up for the clavicle fracture and have their symptoms observed. In approximately $10-15 \%$ of patients there is a concurrent brachial plexus injury that warrants further neurological testing [15].

Persistence of the Moro reflex beyond 4 to 5 months of age occurs in severe neurological problems and most commonly in spastic-type cerebral palsy. Persistence of the Moro reflex beyond 24 months of age indicates a poor prognosis for independent ambulation, especially if sitting balance is not achieved by two years of age [16].

\section{Conclusions}

The Moro reflex is a universal reflex that can provide information to the clinicial on pediatric milestones and, due to its ubiquity, is highly specific 
for potential pathology. Moro reflex can be abnormal due to many factors but is most commonly due to perinatal injury, congenital defect or gestational exposure. A thorough history and physical exam can help identify the cause of the abnormal Moro reflex and help guide corrective treatments.

\section{References}

1. Zafeiriou DI. (2004). Primitive reflexes and postural reactions in the neurodevelopmental examination. Pediatr Neurol. 31(1):1-8.

2. Allen MC, Capute AJ. (1986). The evolution of primitive reflexes in extremely premature infants. Pediatr Res. 20(12):1284-1289.

3. Futagi Y, Toribe Y, Suzuki Y. (2012). The grasp reflex and moro reflex in infants: hierarchy of primitive reflex responses. Int $\mathrm{J}$ Pediatr. 2012:191562.

4. Edwards CW, Al Khalili Y. (2021). Moro Reflex. In: StatPearls. Treasure Island (FL): StatPearls Publishing.

5. Mitchell RG. (1960). The Moro reflex. Cereb Palsy Bull. 2:135141.

6. Parmelee AH. Jr. (1964). A critical evaluation of the Moro reflex. Pediatrics. 33(5):773-788.

7. Rönnqvist L. (1995). A critical examination of the Moro response in newborn infant's symmetry, state relation, underlying mechanisms. Neuropsychologia. 33(6):713-726.
8. Dubowitz LMS, Dubowitz V. (1981). The neurological assessment of the preterm and full-term newborn infant. Clinics in Developmental Medicine. 79:35-38.

9. Halvorson HM. (1937). Studies of the grasping response of early infancy. Journal of Genetic Psychology. 51:371-449.

10. Schott JM, Rossor MN. (2003). The grasp and other primitive reflexes. Journal of Neurology Neurosurgery and Psychiatry. 74(5):558-560.

11. Volpe JJ. Neurology of the Newborn. Philadelphia, Pa, USA: Saunders; 2008. Neurological examination: normal and abnormal features. 121-153.

12. Lou HC. Developmental Neurology. New York, NY, USA: Raven Press; 1982. Cerebral growth spurt. 90.

13. Molnar GE. (1978). Analysis of motor disorder in retarded infants and young children. American Journal of Mental Deficiency. 83(3):213-222.

14. Marquis PJ, Ruiz NA, Lundy MS, Dillard RG. (1984). Retention of primitive reflexes and delayed motor development in very low birth weight infants. J Dev Behav Pediatr. 5(3):124-126.

15. Reiners CH, Souid AK, Oliphant M, Newman N. (2000). Palpable spongy mass over the clavicle, an underutilized sign of clavicular fracture in the newborn. Clin Pediatr (Phila). 39(12):695-698.

16. Ebraheim, Nabil. (2014). Moro Reflex-Everything You Need to Know-DR. Nabil Ebraheim.

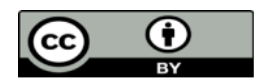

This work is licensed under Creative Commons Attribution 4.0 License

To Submit Your Article Click Here: Submit Manuscript

DOI: $10.31579 / 2768-2757 / 035$
Ready to submit your research? Choose Auctores and benefit from:

$>$ fast, convenient online submission

$>$ rigorous peer review by experienced research in your field

$>$ rapid publication on acceptance

$>$ authors retain copyrights

$>$ unique DOI for all articles

$>$ immediate, unrestricted online access

At Auctores, research is always in progress.

Learn more auctoresonline.org/journals/journal-of-clinical-surgery-andresearch 